\title{
Ladle slag cement - characterization of hydration and conversion
}

Elijah Adesanya $^{\mathrm{a}}$, Harisankar Sreenivasan ${ }^{\mathrm{a}}$, Anu M. Kantola ${ }^{\mathrm{b}}$, Ville-Veikko Telkki ${ }^{\mathrm{b}}$, Katja Ohenoja ${ }^{\mathrm{a}}$, Paivo Kinnunen ${ }^{\mathrm{a}, *}$ and Mirja Illikainen ${ }^{\mathrm{a}}$

${ }^{a}$ Faculty of Technology, Fibre and Particle Engineering Unit, P.O. Box 4300, 90014 University of Oulu, Finland.

${ }^{b}$ NMR Research Group, Faculty of Science, University of Oulu, P.O. Box 4300, 90014 University of Oulu, Finland.

* Corresponding Author: Paivo Kinnunen paivo.kinnunen@oulu.fi+358505646642

${ }^{1}$ In this paper, standard cement chemistry notations were used, hence $\mathrm{CaO}$ represents $\mathrm{C}_{,} \mathrm{Al}_{2} \mathrm{O}_{3}$ as $\mathrm{A}$, $\mathrm{H}_{2} \mathrm{O}$ as $\mathrm{H}$.

\begin{abstract}
Ladle slag, a by-product of steelmaking process, has shown potential to be used as a cementitious material in construction. However, the stability of the hydration products has not been investigated, and has been found to depend on available water. This paper presents the investigation of ladle slag hydration at different waterto-binder ratios. Hydrates of ladle slag converts from metastable to a stable reaction product over a period of time, thus affecting the mechanical and microstructural properties of the hydrated slag. These hydration products were analyzed using TGA, XRD, ${ }^{27} \mathrm{Al}$ NMR, FTIR and SEM techniques. The water-to-binder ratio primarily contributes to the rate at which the conversion process occurs in the system which consequently has a direct effect on the strength derived over a period of time. Through analytical characterization of the microstructure, these hydrates and the conversion process were confirmed, revealing the initial hydrate product of ladle slag to be a metastable dicalcium aluminate octahydrate $\left(\mathrm{C}_{2} \mathrm{AH}_{8}\right)$ which converts to a stable tricalcium aluminate hexahydrate $\left(\mathrm{C}_{3} \mathrm{AH}_{6}\right)$ over a period of time.
\end{abstract}

Graphical Abstract

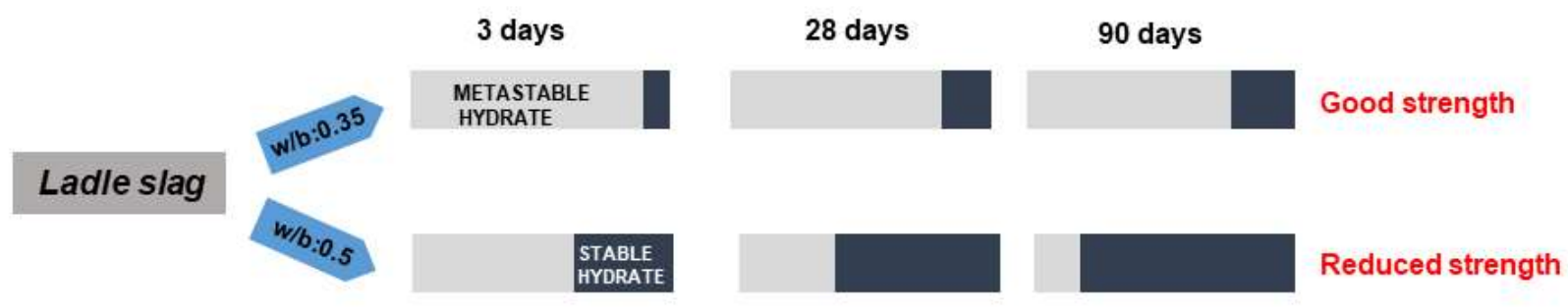

Keywords: Calcium aluminate; Mayenite; Hydration; Thermogravimetry

\section{Introduction}

Ladle slag (LS) is a by-product of steelmaking process which is generally slowly air cooled due to the content of molten steel which is extracted after cooling. Therefore ladle slag is a predominantly crystalline slag with large proportion of fine particles resulting from the breakdown or conversion of larnite $\left(\beta-\mathrm{C}_{2} \mathrm{~S}\right)$ to calcioolivine $\left(\gamma-\mathrm{C}_{2} \mathrm{~S}\right)$ during the cooling process [1]. The chemical composition and mineralogy of ladle slag varies between each plant and production process. Typically it consists of $\mathrm{CaO}, \mathrm{Al}_{2} \mathrm{O}_{3}, \mathrm{SiO}_{2}$, and $\mathrm{MgO}$ and its mineralogical phases are olivine $\left(\gamma-C_{2} S\right)$, mayenite $\left(C_{12} A_{7}\right)$, tricalcium aluminate $\left(C_{3} A\right)$, traces of periclase $(\mathrm{MgO})$ and in some cases free $\mathrm{CaO}$ [1-3]. Calcium aluminates (such as $\mathrm{C}_{12} \mathrm{~A}_{7}$ and $\mathrm{C}_{3} \mathrm{~A}$ ) content in ladle slag varies between plants due to the differences in the de-oxidation process and the type of oxides used [4,5]. 
Ladle slag is known to have hydraulic properties, which means that it reacts with water to produce cementlike hydration products. $\gamma-\mathrm{C}_{2} \mathrm{~S}$ is poorly hydraulic under normal hydration conditions, however $\mathrm{C}_{12} \mathrm{~A}_{7}$ is known to be highly hydraulic, reacting quickly when in contact with water [6]. Based on chemical composition and reaction mechanism, ladle slag can be compared with calcium aluminate cement (CAC) which is a high-value cement used in niche applications, such as refractories, rapid-hardening repair mortars, floor levelers and in orthopedics $[7,8]$. Therefore, the hydration reactions in CAC cements are well-understood, and due to the mineralogical similarities between LS and CAC, the hydration of ladle slag could be further understood. Typically, calcium aluminate cement is characterized by high content of aluminium and calcium, with the main reactive phase identified as CA. Similarly, LS is also characterized by high content of calcium (Fig.1) and aluminium, which suggests likely formation of calcium aluminates hydrates as the main phases during hydration. In a previous study [9], the similarity in reactivity mechanism has been ascertained of ladle slag and CAC. The main reactive phase in ladle slag is mayenite $\left(\mathrm{C}_{12} \mathrm{~A}_{7}\right)$ which favors the formation of $\mathrm{C}_{2} \mathrm{AH}_{8}$ as the initial hydration products $[1,8,9]$ rather than calcium aluminate decahydrate $\left(\mathrm{CAH}_{10}\right)$. The sequence of hydration and conversion is shown in equation 1-2.

$\mathrm{C}_{12} \mathrm{~A}_{7}+51 \mathrm{H} \rightarrow 6 \mathrm{C}_{2} \mathrm{AH}_{8}+\mathrm{AH}_{3}$

$3 \mathrm{C}_{2} \mathrm{AH}_{8} \rightarrow 2 \mathrm{C}_{3} \mathrm{AH}_{6}+\mathrm{AH}_{3}+9 \mathrm{H}$

The conversion from eq. 1 to 2 is accompanied by a change in the crystal structure of the hexagonal metastable $\left(\mathrm{C}_{2} \mathrm{AH}_{8}\right)$ to a cubic stable hydrate $\left(\mathrm{C}_{3} \mathrm{AH}_{6}\right)$ which has different densities of 1750 and $2520 \mathrm{~kg} / \mathrm{m}^{3}$ respectively [6]. Therefore, there occurs a significant change in the volume of the solids in the hydrated slag with a more porous structure and a consequent decrease in strength. Additionally, the water released after the conversion in eq. 2 is readily available to react with the unreacted anhydrous slag when the water-to-binder ratio is initially low to form more $\mathrm{C}_{2} \mathrm{AH}_{8}$ which leads to increase in strength. Hydration reaction of $\mathrm{CAC}$ and the conversion of metastable reaction products to stable products have been studied [8,10-13]. The formed hydrates known by their chemical formulas are calcium aluminate decahydrate $\left(\mathrm{CAH}_{10}\right)$, dicalcium aluminate octahydrate $\left(\mathrm{C}_{2} \mathrm{AH}_{8}\right)$, tricalcium aluminate hexahydrate $\left(\mathrm{C}_{3} \mathrm{AH}_{6}\right)$ and gibbsite $\left(\mathrm{AH}_{3}\right)[8,14]$. These hydrates are metastable $\left(\mathrm{CAH}_{10}\right.$ and $\left.\mathrm{C}_{2} \mathrm{AH}_{8}\right)$ and gradually convert to stable and permanent hydrates $\left(\mathrm{C}_{3} \mathrm{AH}_{6}\right.$ and $\left.\mathrm{AH}_{3}\right)$. Consequently, when this conversion to a more stable and dense hydrates occurs it leads to an increase in porosity and a decrease in strength of the concrete. Further insight on these reaction development have been clearly studied and reported $[8,12]$.

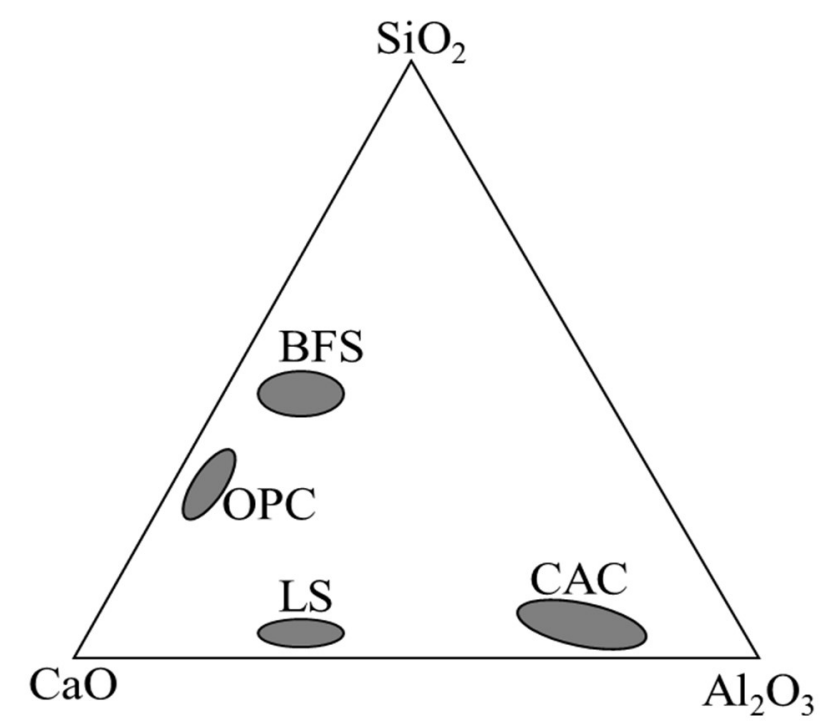

Fig. 1. Chemical composition of LS in the ternary system compared with other $\mathrm{CaO}-\mathrm{SiO}_{2}-\mathrm{Al}_{2} \mathrm{O}_{3}$ binders. 
However, fewer studies have reported about the conversion of ladle slag hydrates and the mechanism behind the process. Adolfsson et al. [5] studied the effect of mineralogy on ladle slag hydration using water-to-binder ratio $(\mathrm{w} / \mathrm{b})$ of 0.5 . In mineralogical analyses of ladle slag, they identified major crystalline phases to be pleochroite/Q-phase $\left(\mathrm{C}_{20} \mathrm{~A}_{13} \mathrm{M}_{3} \mathrm{~S}_{3}\right), \mathrm{C}_{12} \mathrm{~A}_{7}$ and $\mathrm{C}_{3} \mathrm{~A}$. The authors observed a decline in strength at 28 days up to $37 \%$ of the achieved strength at 7 days. It was suggested that the neat ladle slag should be blended with ground granulated blast furnace slag (GGBFS) to avoid the conversion of the reaction products and favoring formation of stratlingite $\left(\mathrm{C}_{2} \mathrm{ASH}_{8}\right)$. However, the impact of water-to-binder ratio on ladle slag hydration products and their conversion has not been studied previously. Ladle slag is a promising cement-like binder material. In our previous study [9], we observed a decrease in strength at 28 days in the alkali activated ladle slag mortars, and later an increase in strength at 56 and 90 days. The later strength development was attributed to the diffusion of reactive silica from diatomaceous earth to form a CASH like product. Furthermore, different methods have been utilized or suggested for enhancing the mineralogy and the vitreous phase of ladle slag. In a study by Choi et al [2], molten ladle slag was rapidly air cooled using high pressured air. They reported removal of free- $\mathrm{CaO}$ or free- $\mathrm{MgO}$ and an increase in the amorphous content of the slag after rapid air cooling, which also led to stable hydration products when mixed with water. Similar process was also suggested by Adolfsson et al. [15]. However, rapid cooling of ladle slag is not effective according to the producers, because during the extraction from the furnace the molten slag still contains steel and its separation becomes difficult after rapid cooling. Also, heating up the as-received slag to temperatures between $1000-1200{ }^{\circ} \mathrm{C}$ and then rapid cooling adds to its environmental footprint and may not be economically efficient.

The main drawback of using ladle slag in cementitious materials is the risk for uncontrolled conversion of calcium aluminate hydrates during hardening. Therefore, in this study, we attempt to optimize the water amount in order to prevent or minimize the conversion of ladle slag hydrates and also study its similarities with CAC. We aim to contribute to the better understanding of ladle slag hydration. The effect of hydrates conversion was confirmed through strength of the paste samples at 3, 7, 28 and 90 days. In order to achieve detail analysis of the metastable and stable hydration products, various analytical methods were used. Thermogravimetric analysis (TGA) was done to determine the type of hydrates [8], scanning electron microscopy (SEM) to show the change in crystals structures and x-ray diffraction, (XRD) to confirm the mineralogy of the slag before and after conversion. In addition, solid-state nuclear magnetic resonance (NMR) spectroscopy of ${ }^{27} \mathrm{Al}$ was used to analyze complex cement hydration including CAC hydration processes $[16,17]$.

\section{Materials and methods}

\subsection{Materials}

The chemical composition of the slowly cooled ladle slag (LS) that was used in the studies is presented in Table 1. Free $\mathrm{CaO}$ for the LS was measured to be $0.4 \mathrm{wt} . \%$ using the method in the standard EN 450-1 [21]. The major mineralogy phases of ladle slag are $\gamma-C_{2} S, C_{12} A_{7}, C_{3} A$ and minor traces of periclase (See Fig 2). Calcium aluminate content of the slag has been previously analyzed to be $53.3 \mathrm{wt} . \%$ and an amorphous content of $21.3 \mathrm{wt} . \%$ [9]. The received LS had median particle size $\left(\mathrm{d}_{50}\right)$ of about $34 \mu \mathrm{m}$ and was further ball milled to achieve $\mathrm{d}_{50}$ below $10 \mu \mathrm{m}$ determined using laser diffraction technique (Beckman Coulter LS 13320). Analytical grade citric acid (C1949, Tokyo Chemical Industry Co., Ltd., Japan) was used as retarder.

Table 1. Chemical composition of ladle slag (\% of mass).

\begin{tabular}{cccccclll}
\hline & $\mathrm{CaO}$ & $\mathrm{Al}_{2} \mathrm{O}_{3}$ & $\mathrm{SiO}_{2}$ & $\mathrm{MgO}$ & $\mathrm{Fe}_{2} \mathrm{O}_{3}$ & $\mathrm{SO}_{3}$ & Others & LOI $\left(950^{\circ} \mathrm{C}\right)$ \\
\hline $\mathrm{LS}$ & 50.9 & 27.8 & 8.3 & 6.3 & 1.1 & 0.8 & 4.8 & -0.9 \\
\hline
\end{tabular}




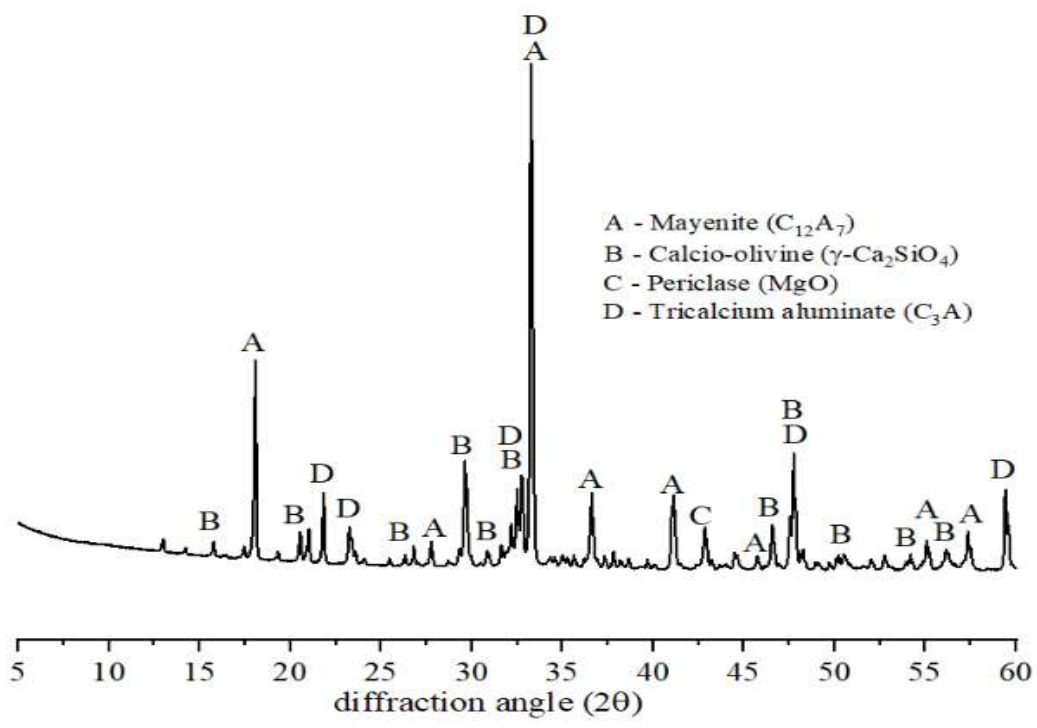

Fig.2. XRD diffractograms for LS.

\subsection{Sample preparation}

The hydration of the LS was studied using water to binder $(\mathrm{w} / \mathrm{b})$ ratios of $0.35,0.40,0.45$ and 0.50 . The demineralized water used contained $1 \mathrm{wt} . \%$ of citric acid, used as a setting retarder. The paste was then prepared by adding the water to the slag and mixed using a shear mixer (IKA Eurostar 20) for 4 minutes. The paste was then cast in a $20 \times 20 \times 80 \mathrm{~mm}$ stainless steel moulds, sealed and stored at room temperature before demolding after $24 \mathrm{hrs}$. Thereafter the samples were kept in moist conditions at $95 \% \pm 3$ relative humidity and $22 \pm 3{ }^{\circ} \mathrm{C}$ until testing time. The unconfined compressive strength (UCS) was measured at 3, 7, 28 and 90 days using Zwick testing machine with a maximum load of $100 \mathrm{kN}$ employing a loading force of $2.4 \mathrm{kN} / \mathrm{s}$. At each testing date, four replicates were crushed and the average is reported $\mathrm{s}$ the compressive strength.

\subsection{Testing methods}

The characterization and analytical tests were performed at 3,28 and 90 days' age of the samples After each strength tests, the samples were further crushed to sub-100 $\mu \mathrm{m}$ pieces and then immersed in acetone to stop the hydration. The saturated samples were then removed after $24 \mathrm{hrs}$ and dried at room temperature before they were then placed in a desiccator until analysis time. The samples were further finely ground using Retsch vibratory disc mill (RS 200) for the analyses. Thermogravimetric analysis (TGA) was undertaken using Precisa Gravimetrics AG "prepASH automatic drying and ashing system". Samples were heated from room temperature to $700^{\circ} \mathrm{C}$ at $10^{\circ} \mathrm{C} / \mathrm{min}$ in an inert nitrogen atmosphere. The TGA/DTG curves were de-convoluted using origin software.

Scanning electron microscope (SEM) analysis was performed using a Zeiss Sigma microscope to analyze the microstructure morphology of the samples for platinum coated samples. The analyzed samples used were broken pieces of the hardened specimen. X-ray diffraction analysis was performed using Rigaku SmartLab 9 $\mathrm{kW}$ x-ray diffraction equipment. The analysis employed $\mathrm{Cu} \mathrm{K \alpha}$ radiation $(\mathrm{K} \alpha 1=1.78892 \AA$; $\mathrm{K} \alpha 2=1.79278$ $\AA ; \mathrm{K} \alpha 1 / \mathrm{K} \alpha 2=0.5)$, at a scan rate of $3^{\circ} / \mathrm{min}$ in the range $5^{\circ}-90^{\circ}(2 \theta)$, and $0.02^{\circ}$ step. Phase identification was done using "X'pert HighScore Plus" (PANalytical software). The ${ }^{27} \mathrm{Al}$ NMR spectra were obtained with a Bruker Avance III 300 spectrometer operating at $78.24 \mathrm{MHz}$ for ${ }^{27} \mathrm{Al}$. For the MAS experiments the samples were packed into $7 \mathrm{~mm}$ zirconia rotors, rotation frequency of $7 \mathrm{kHz}$ was applied and 2048 scans were accumulated with a repetition rate of two seconds. (No proton decoupling nor cross polarization was used). The chemical shifts were referenced to $\mathrm{Al}\left(\mathrm{NO}_{3}\right)_{3}$ set to zero ppm.

\section{Results and discussion}

3.1. Effect of water-to-binder ratio on the strength 
The amount of water was found to have a profound effect on the strength development; in addition to the expected inverse correlation with strength, the strength development profile was affected as well (Fig. 3). The effect of conversion was clear with water to binder ratio higher than 0.35 , where compressive strength at 28 days was lower than at 3 days. At 28 days, the compressive strength for both LS/ 0.45 and 0.50 decreased by approximately $50 \%$ and $46 \%$ respectively compared with their strength at 3 days. While for LS/ 0.40 , the reduction in strength was evident and significant at day 28 , losing $50 \%$ of its strength at 3 days. Furthermore, LS/ $/ 35$ showed an increase in strength at 7 days, then a $20 \%$ strength loss at 28 days. However, the strength at all later ages where higher when compared with strength at 3 days. However, it can be observed that at 90 days, all samples showed slight recovery in strength compared with significant strength reduction at 28 days.

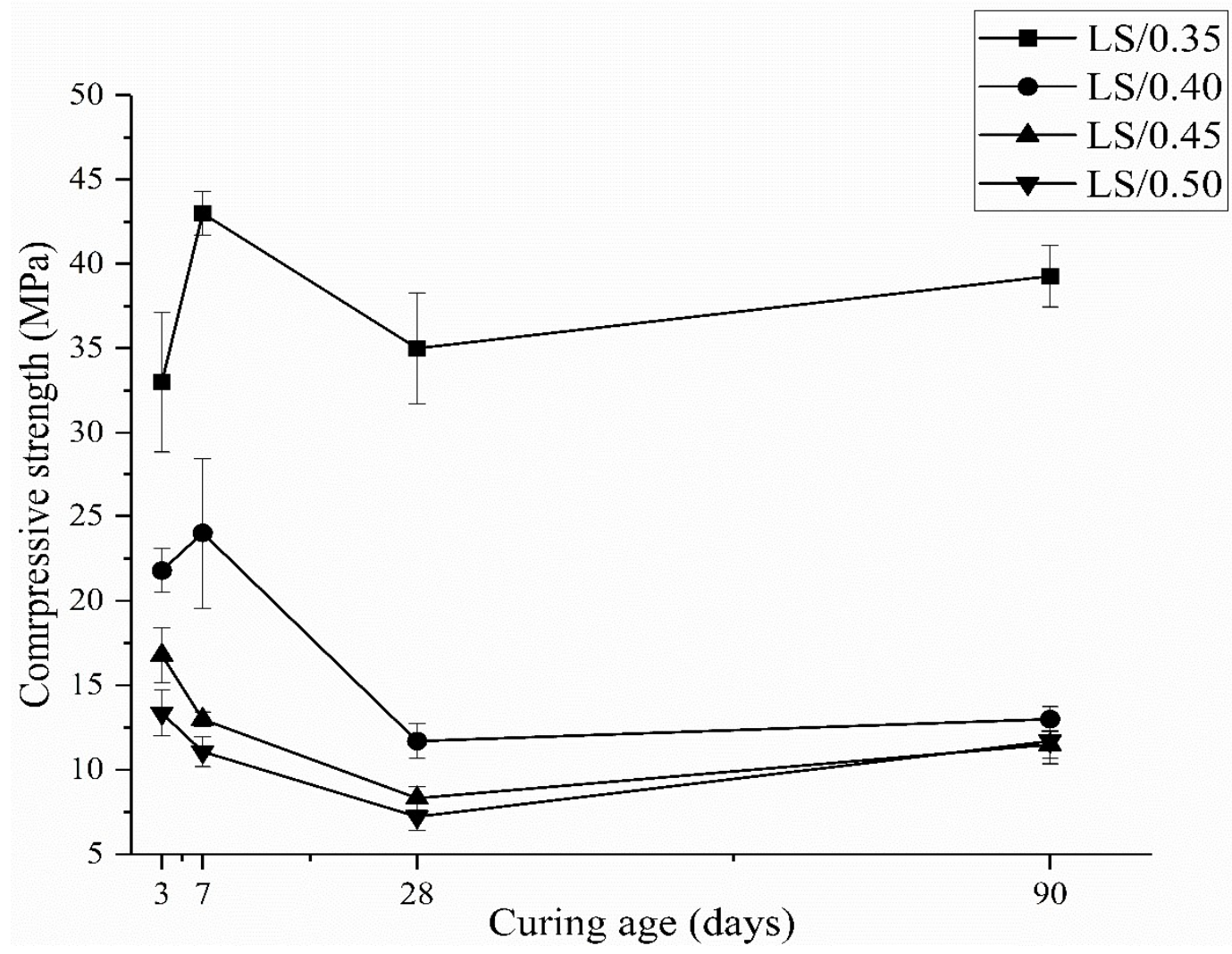

Fig.3. Impact of water-to-binder ratio on compressive strength at various ages

\subsection{Thermogravimetry analysis of hydrated ladle slag}

Differential thermogravimetric (DTG) analysis was used to identify the hydration products and to explain the conversion mechanism in the hydrated LS pastes. This method is preferred and widely used in CAC studies to identify and estimate the change in hydration products by the value of their decomposition temperatures. A comparatively range of dehydration temperatures are reported for CAC hydrates in the literature [18,19]: The metastable phases (i.e. $\mathrm{C}_{2} \mathrm{AH}_{8}$ ) have decomposition peaks in the temperature range $100-200{ }^{\circ} \mathrm{C}$, while the stable hydration products $\left(\mathrm{AH}_{3}\right.$ and $\left.\mathrm{C}_{3} \mathrm{AH}_{6}\right)$ have decomposition peaks in the temperature range 200-250 and 300-380 ${ }^{\circ} \mathrm{C}$, respectively.

It is evident from the thermogravimetric analysis, that conversion was affected by W/B ratio. Fig. $4 \mathrm{a}$ and $4 \mathrm{~b}$ shows the thermograms of LS/0.35 and LS/0.50, at 3, 28 and 90 days. The conversion of LS can be analyzed as the increase in the intensities of the peaks for $\mathrm{AH}_{3}$ or $\mathrm{C}_{3} \mathrm{AH}_{6}$ and decrease in the intensities of the peaks for $\mathrm{C}_{2} \mathrm{AH}_{8}$. In Fig.4a, the first dehydration peak at $180-240{ }^{\circ} \mathrm{C}$ indicates the presence of $\mathrm{C}_{2} \mathrm{AH}_{8}$ [19]. This peak grew in intensity from 3 days to a broad maximum at 90 days. This peak is at all days higher than the 
corresponding peak for decomposition of $\mathrm{C}_{3} \mathrm{AH}_{6}$ at $350{ }^{\circ} \mathrm{C}$, the minimal effect of conversion in this system and the growth of $\mathrm{C}_{2} \mathrm{AH}_{8}$ during this period is suggested to be partly due to continuous hydration of unreacted LS which negates the net conversion produced simultaneously during the same period. Scrivener [8], proposed that if the initial $\mathrm{w} / \mathrm{b}$ is kept low, some anhydrous slag will remain after the initial formation of the metastable hydrates which is then available to react with water released during the conversion process, which as a result increases the strength as applicable with LS/0.35 strength at 90 days. Furthermore, in Fig.4b broad peak with overlapping peaks can be identified between $200-380{ }^{\circ} \mathrm{C}$ at 3 days. It is noteworthy that both $\mathrm{AH}_{3}$ and $\mathrm{C}_{3} \mathrm{AH}_{6}$ tend to overlap due to their decomposition peaks proximity which complicates the peak assignment [11]. However, at 28 days there is a clear change in the intensities of these peaks with $\mathrm{C}_{2} \mathrm{AH}_{8}$ identified by a short peak at $180{ }^{\circ} \mathrm{C}$ with a shoulder at $220^{\circ} \mathrm{C}$ indicating to dehydration of $\mathrm{AH}_{3}$. Consequently, at 90 days the clear increase of the intensities of the stable product and a reduction in the intensity of the metastable product showed significant conversion occurring. These analyses are consistent with the strength behavior of the specimens (Fig 3). However, the complete conversion of these metastable product during the period used in this investigation is uncertain due to the continuous existence of $\mathrm{C}_{2} \mathrm{AH}_{8}$ in the peak for $\mathrm{LS} / 0.50$ at 90 days (Fig.4b).
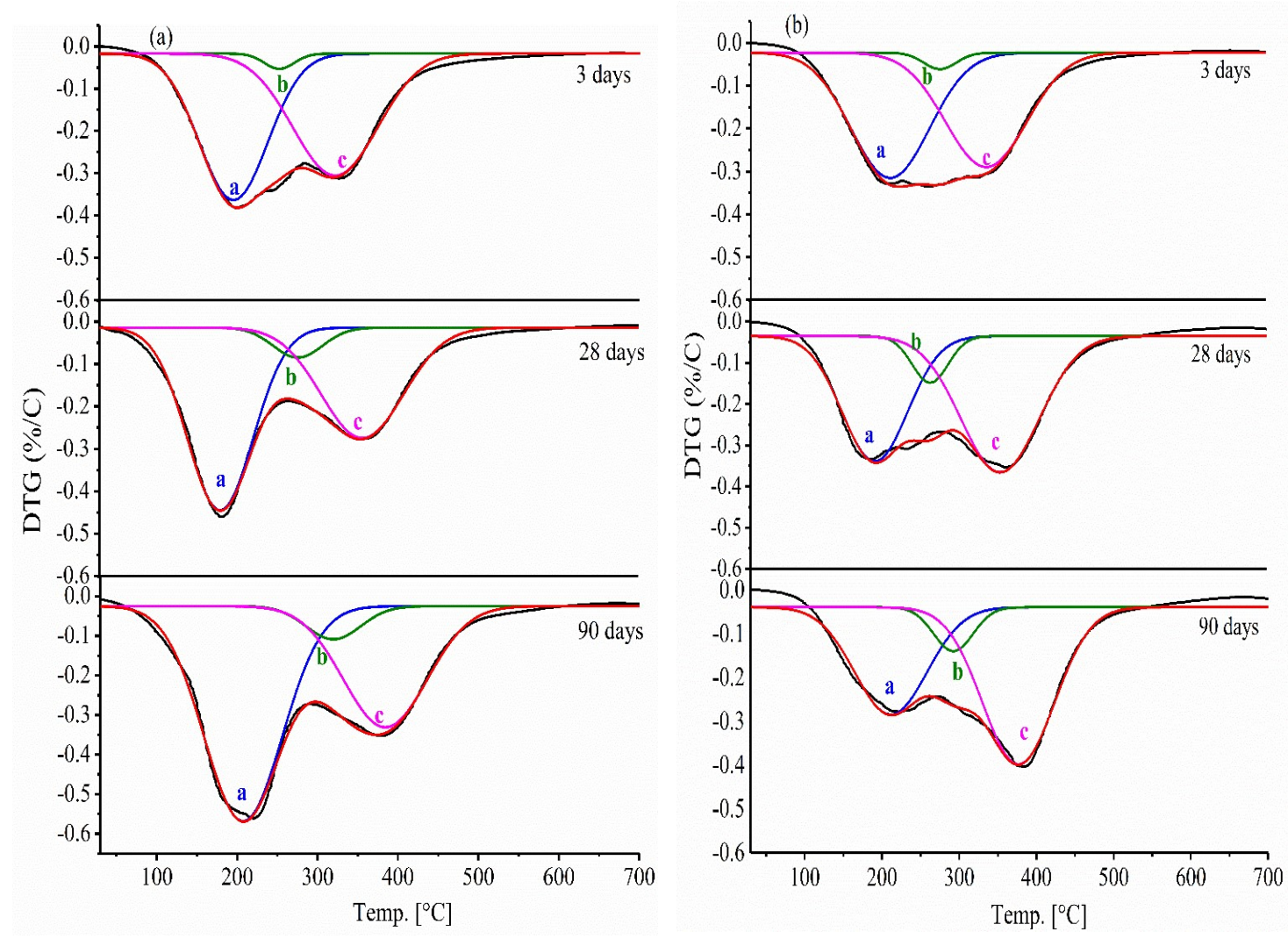

Fig. 4. DTG curves for the hydrated ladle slag (a) LS/0.35 and (b) LS/0.50. Where $a=\mathrm{C}_{2} \mathrm{AH}_{8}, \mathrm{~b}=\mathrm{AH}_{3}$ and $\mathrm{c}$ $=\mathrm{C}_{3} \mathrm{AH}_{6}$.

\subsection{Microstructure}

The morphological changes that occur before and after the conversion was determined through SEM analysis illustrated in Fig.5a and 5b. The microstructure of LS/0.35 at 3 days (Fig.5a) shows predominantly plate-like shaped and clusters of spherical crystal structures embedded together in the paste. These crystals are identified with the initial hydrate $\mathrm{C}_{2} \mathrm{AH}_{8}$, which in its unique structure exist as flat hexagonal plates [8,11,14]. At 28 days after fractional conversion, the microstructure (Fig.5b) shows similar clusters identified at 3 days as the hydrate $\mathrm{C}_{2} \mathrm{AH}_{8}$. Also a cubic structure crystal, which is typical for the hydrogarnet $\mathrm{C}_{3} \mathrm{AH}_{6}$ [11], was observed.

Fig. 6 shows the microstructure of LS/0.50 at 3 and 28 days. When comparing the figures, it can be seen the change in microstructure as a result of conversion. In Fig.6a, both $\mathrm{C}_{2} \mathrm{AH}_{8}$ and $\mathrm{C}_{3} \mathrm{AH}_{6}$ can be identified. The 
presence of $\mathrm{C}_{3} \mathrm{AH}_{6}$ confirms that conversion of the metastable hydrate already started at 3 days. However, at 28 days (Fig.6b) the microstructure shows increased amount of $\mathrm{C}_{3} \mathrm{AH}_{6}$ identified by its cubic structure which may suggest an increase in conversion in this sample when compared with LS/0.35. As seen in Fig. 6b, the structure also exhibits an increase in porosity due to the release of water and change in specific gravities of the hydrates during conversion which consequently reduces the strength. It is also assumed that the conversion of the flat plates of $\mathrm{C}_{2} \mathrm{AH}_{8}$ to a cubic morphology disrupts the intercrystalline bonds in the microstructure due to the poor bonding ability of the hydrogarnet $\left(\mathrm{C}_{3} \mathrm{AH}_{6}\right)$ and its smaller surface area [20].
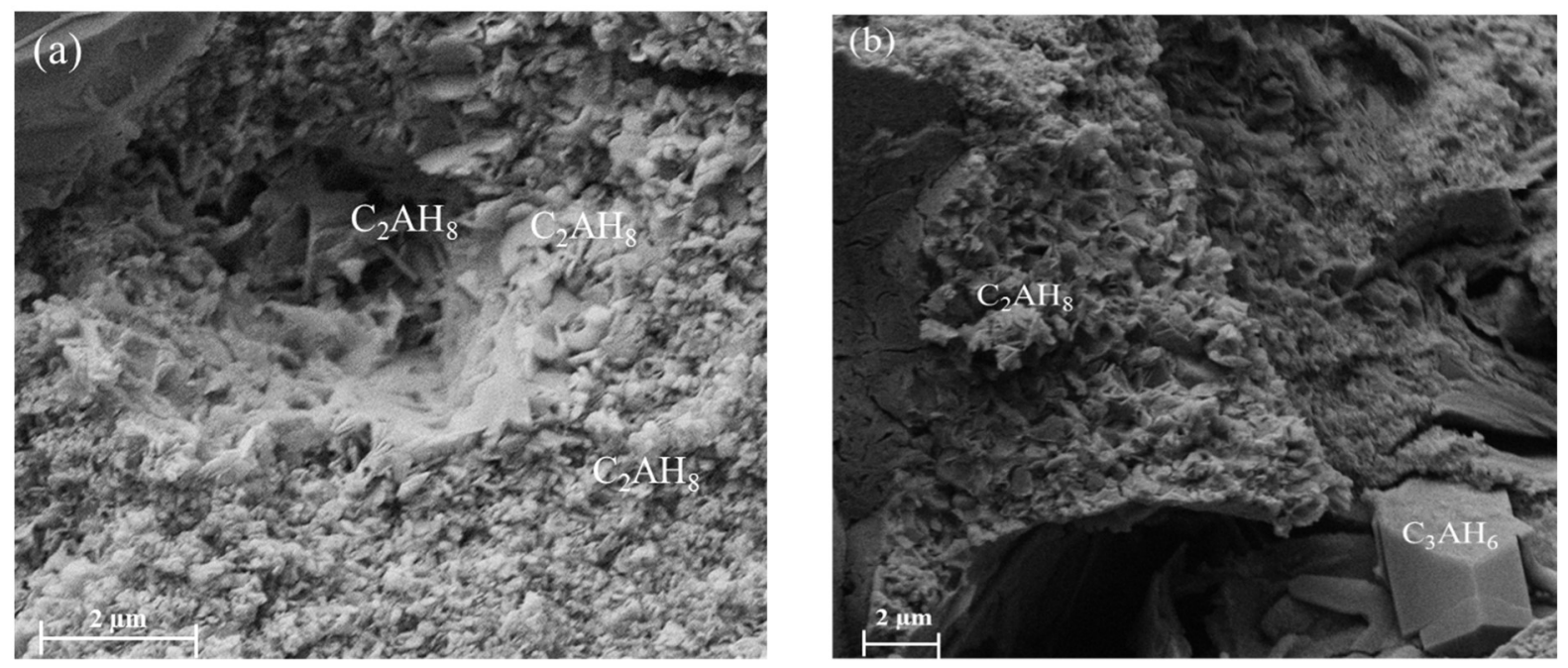

Fig.5. Microstructures of the LS/0.35 paste at (a) 3 days, and (b) 28 days.
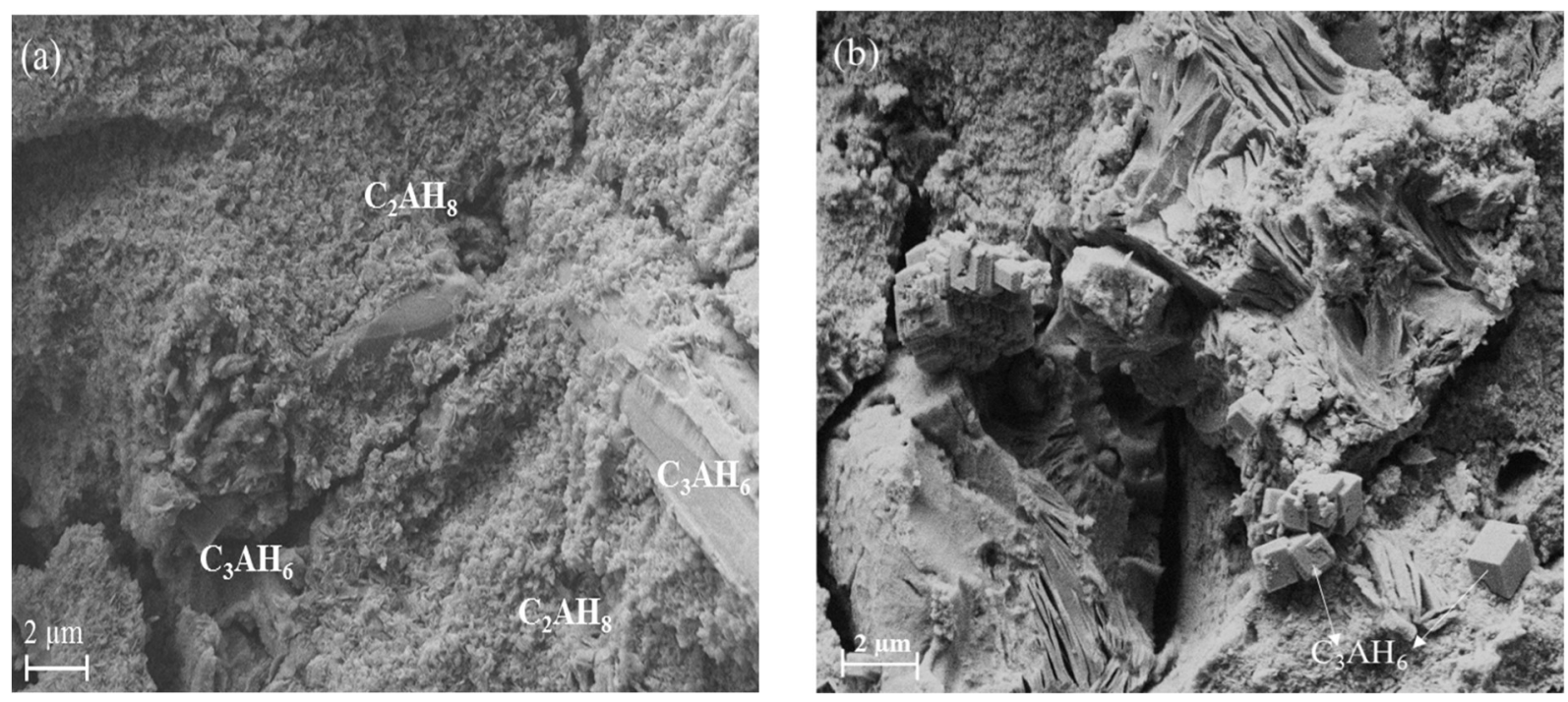

Fig.6. Microstructures of the LS/0.5 paste at (a) 3 days, and (b) 28 days.

\subsection{X-ray diffraction}

The X-ray patterns of the hydrated LS at various ages show highly crystalline phases (Fig.7). The XRD patterns show similar pattern as the anhydrous LS except for few newly formed peaks. XRD for LS/0.35 reveal the formation of new peak at $7.1^{\circ} 2 \theta$ which was registered as $\mathrm{C}_{2} \mathrm{AH}_{8}$ and another phase peak at $17.1^{\circ} 2 \theta, 20.2^{\circ} 2 \theta$, $38.1^{\circ} 2 \theta$ and $44.3^{\circ} 2 \theta$ registered as katoite $\left(\mathrm{C}_{3} \mathrm{AH}_{6}\right)$. When comparing $\mathrm{C}_{2} \mathrm{AH}_{8}$ peaks in the three diffractograms (Fig.7a), an increment in the peak intensity can be observed after 3 days. $\mathrm{C}_{3} \mathrm{AH}_{6}$ peaks on the other hand, had lower intensities at both 3 and 38 days. However, $\mathrm{C}_{3} \mathrm{AH}_{6}$ peaks at 90 days increased moderately compared with 3 and 28 days. Also in Fig. $7 \mathrm{~b}$, an increase in the $\mathrm{C}_{3} \mathrm{AH}_{6}$ peak is observed after 3 days of hydration with a maximum at 90 days. It can also be observed that the peaks for $\mathrm{C}_{2} \mathrm{AH}_{8}$ has a lower intensity compared with 
LS/0.35. Although, the intensities cannot accurately predict the amount of the crystalline phases discussed, it can however propose the evolution of the phases at these days the samples were analyzed.

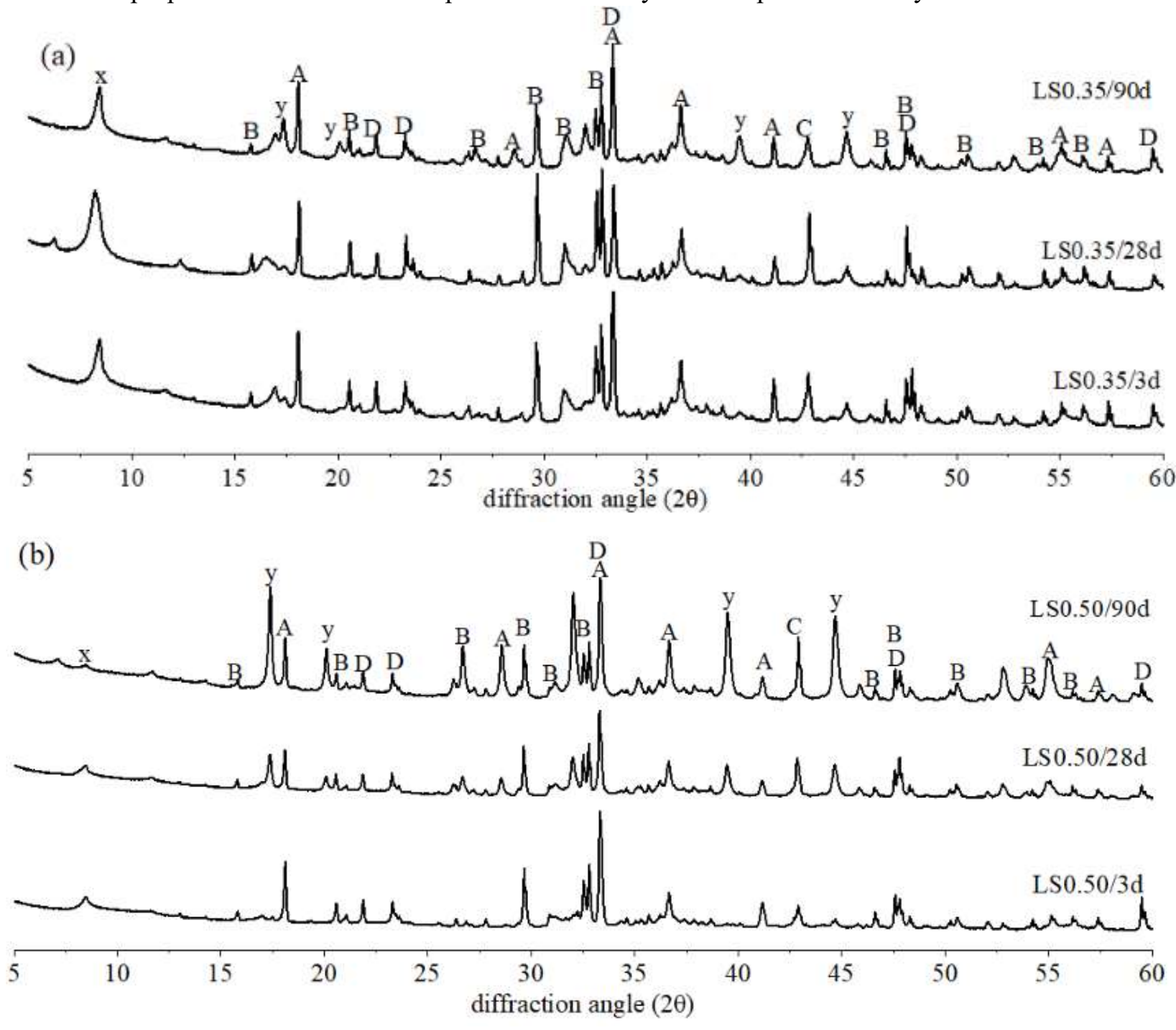

Fig. 7. X-ray diffractograms (a) LS/0.35 and (b) LS/0.50 at 3, 28 and 90 days. Letters indicates phases identified: A-mayenite $\left(\mathrm{C}_{12} \mathrm{~A}_{7}\right)$, B-calcio-olivine $\left(\gamma-\mathrm{C}_{2} \mathrm{~S}\right)$, C-periclase $(\mathrm{MgO})$, D-tricalcium aluminate $\left(\mathrm{C}_{3} \mathrm{~A}\right)$, $\mathrm{x}$-dicalcium aluminate hydrate $\left(\mathrm{C}_{2} \mathrm{AH}_{8}\right)$ and y-katoite $\left(\mathrm{C}_{3} \mathrm{AH}_{6}\right)$.

\subsection{Solid-state NMR spectroscopy}

${ }^{27} \mathrm{Al}$ MAS NMR spectra shows three aluminium coordination $\left(\mathrm{Al}^{\mathrm{IV}}, \mathrm{Al}^{\mathrm{V}}\right.$ and $\left.\mathrm{Al}{ }^{\mathrm{VI}}\right)$ identifiable between the chemical shifts 52 and $80 \mathrm{ppm}, 30$ and $40 \mathrm{ppm}$, and -10 and $20 \mathrm{ppm}$, respectively [17,22]. The spectrum of the LS showed a wide, intense peak at $70 \mathrm{ppm}$ due to the $\mathrm{C}_{12} \mathrm{~A}_{7}$ present in the slag [23] and the less intense broad peak centered at $10 \mathrm{ppm}$ indicating slight hydration of LS during storage. For the hydrated $\mathrm{LS} / 0.35$, the $\mathrm{Al}^{\mathrm{IV}}$ region reduced significantly due to the reaction of $\mathrm{C}_{12} \mathrm{~A}_{7}$ (Fig. 8a), and also a substantial increment in the $\mathrm{Al}^{\mathrm{VI}}$ region as a result of the formation of the stable and metastable products can be observed. The ${ }^{27} \mathrm{Al}$ MAS-NMR spectra for this sample contain peaks near $10 \mathrm{ppm}$, which is consistent with the formation of the hexagonal hydrate phase $\mathrm{C}_{2} \mathrm{AH}_{8}$ [16]. This also confirms the initial hydration product of $\mathrm{LS}$ to be $\mathrm{C}_{2} \mathrm{AH}_{8}$ and not $\mathrm{CAH}_{10}$. The decline in the shift of the signal between 3 days $(10.8 \mathrm{ppm})$ and 90 days $(10.5 \mathrm{ppm})$, may indicate continuous formation of the hexagonal hydrates. Furthermore, the partially hydrated slag yielded small signals in the $70 \mathrm{ppm}$ range due to unhydrated reactants. 
The spectra of LS/0.50 (Fig. 8b) contains peaks near 12 ppm associated with the formation of the cubic hydrate phase $\mathrm{C}_{3} \mathrm{AH}_{6}[16,24]$ consistent with the phase identified through thermogravimetry (Fig. 4) and SEM (Fig.5). In addition, the signal increased after 3 days towards a maximum $(12.2 \mathrm{ppm})$ at 90 days confirming the continuous conversion of $\mathrm{C}_{2} \mathrm{AH}_{8}$ to $\mathrm{C}_{3} \mathrm{AH}_{6}$. The small hump in the $70 \mathrm{ppm}$ range is attributed to the unhydrated reactants.
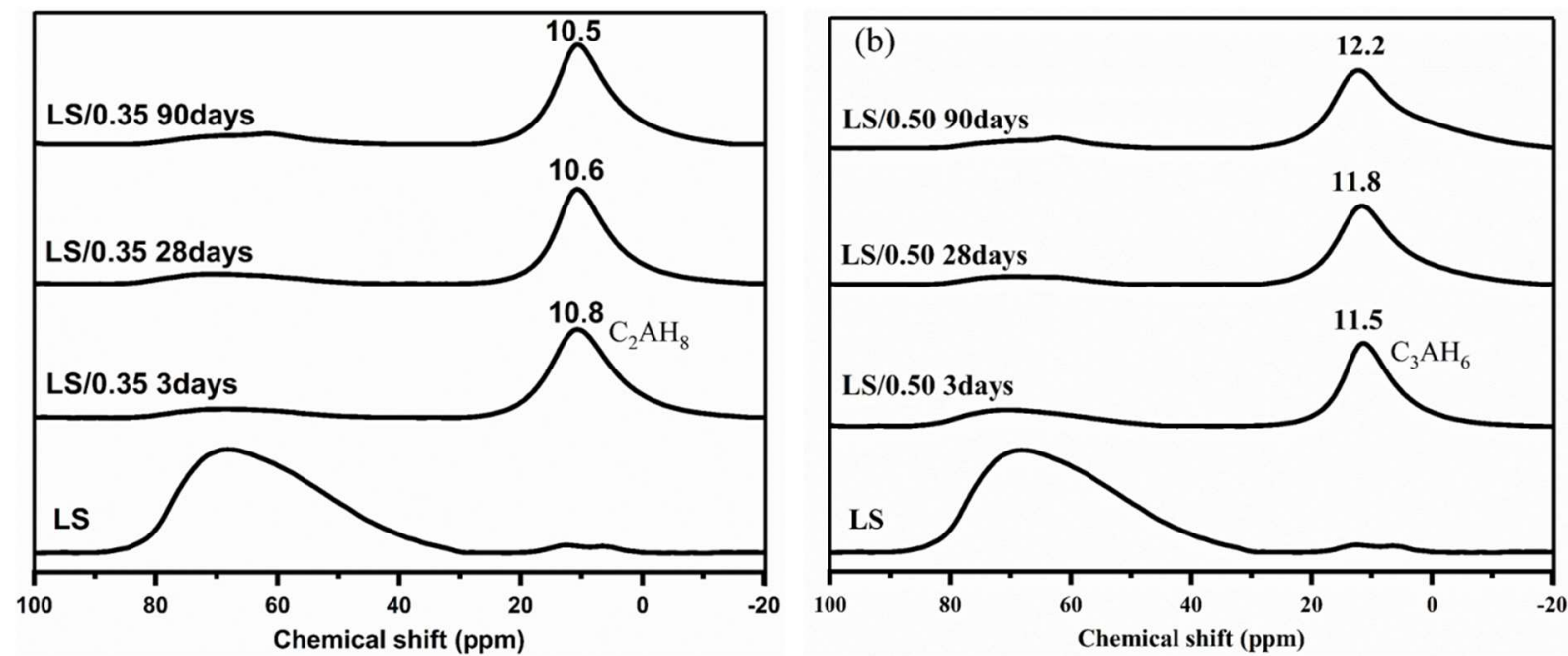

Fig $8 .{ }^{27} \mathrm{Al}$ MAS NMR spectra of the anhydrous and hydrated LS at 3, 28 and 90 days.

\section{Conclusion}

Understanding the hydration process of ladle slag is important towards its commercial utilization. Here, we studied the effects of water-to-binder ratio on the physical and chemical properties of hydrated ladle slag. Results showed the conversion of the metastable hydrate $\left(\mathrm{C}_{2} \mathrm{AH}_{8}\right)$ to a stable hydrate $\left(\mathrm{C}_{3} \mathrm{AH}_{6}\right)$ during the period of analysis similar to the mechanism during the hydration of calcium aluminate cement. By lowering the waterto-binder ratio in the hydrated ladle slag, the conversion of these hydrates was moderately reduced. However, in future applications and utilization of this slag, the reduction in strength based on the water-to-binder ratio should be considered to achieve the concrete strength required. To conclude, the findings in this study significantly add to the understanding of the properties of ladle slag hydration and systematic behavior of the slag towards its utilization. It also sheds light on the similarities between the hydration of LS and calcium aluminate cements. Future works should investigate on how to more fully eliminate conversion in this slag hydration system.

\section{Acknowledgement}

This work was funded by the European Regional Development Fund (A70189) under the auspices of the MINSI project by the following companies: SSAB Europe Oy, Ekokem Oy, Stora Enso Oy, Pohjolan Voima Oy and Oulun Energia. The authors would like to thank Jarno Karvonen and Jani Österlund for their contribution to the laboratory work.

\section{References}

[1] C. Shi, Characteristics and cementitious properties of ladle slag fines from steel production, Cem. Concr. Res. 32 (2002) 459-462. doi:10.1016/S0008-8846(01)00707-4.

[2] S. Choi, J.-M. Kim, D. Han, J.-H. Kim, Hydration properties of ladle furnace slag powder rapidly cooled by air, Constr. Build. Mater. 113 (2016) 682-690. doi:10.1016/j.conbuildmat.2016.03.089. 
[3] J. Setién, D. Hernández, J.J. González, Characterization of ladle furnace basic slag for use as a construction material, Constr. Build. Mater. 23 (2009) 1788-1794.

doi:10.1016/j.conbuildmat.2008.10.003.

[4] I.Z. Yildirim, M. Prezzi, Chemical, Mineralogical, and Morphological Properties of Steel Slag, Adv. Civ. Eng. 2011 (2011) e463638. doi:10.1155/2011/463638.

[5] D. Adolfsson, R. Robinson, F. Engström, B. Björkman, Influence of mineralogy on the hydraulic properties of ladle slag, Cem. Concr. Res. 41 (2011) 865-871. doi:10.1016/j.cemconres.2011.04.003.

[6] A.J. Majumbar, B. Singh, R.N. Edmonds, Hydration of mixtures of C12A7 and granulated blastfurnace slag, Cem. Concr. Res. 19 (1989) 848-856. doi:10.1016/0008-8846(89)90097-5.

[7] R.M. Parreira, T.L. Andrade, A.P. Luz, V.C. Pandolfelli, I.R. Oliveira, Calcium aluminate cementbased compositions for biomaterial applications, Ceram. Int. 42 (2016) 11732-11738. doi:10.1016/j.ceramint.2016.04.092.

[8] K. Scrivener, Calcium aluminate cements, in: Adv. Concr. Technol. 1 Const. Mater., ButterworthHeinemann, Oxford, 2003: p. P2/2-2/19.

[9] E. Adesanya, K. Ohenoja, P. Kinnunen, M. Illikainen, Properties and durability of alkali-activated ladle slag, Mater. Struct. 50 (2017) 255. doi:10.1617/s11527-017-1125-4.

[10] I. Odler, Special Inorganic Cements, CRC Press, 2003.

[11] C. Bradbury, P.M. Callaway, D.D. Double, The conversion of high alumina cement/concrete, Mater. Sci. Eng. 23 (1976) 43-53. doi:10.1016/0025-5416(76)90085-9.

[12] H.G. Midgley, A. Midgley, The conversion of high alumina cement, Mag. Concr. Res. 27 (1975) 5977. doi:10.1680/macr.1975.27.91.59.

[13] S.M. Bushnell-Watson, J.H. Sharp, The application of thermal analysis to the hydration and conversión Reactions of calcium alumínate Cements, Mater. Constr. 42 (1992) 13-32.

[14] P. Barnes, J. Bensted, Structure and Performance of Cements, Second Edition, Chapter 4, CRC Press, 2002.

[15] D. Adolfsson, F. Engström, R. Robinson, B. Björkman, Cementitious Phases in Ladle Slag, Steel Res. Int. 82 (2011) 398-403. doi:10.1002/srin.201000176.

[16] X. Cong, R.J. Kirkpatrick, Hydration of Calcium Aluminate Cements: A Solid-State 27 Al NMR Study, J. Am. Ceram. Soc. 76 (n.d.) 409-416. doi:10.1111/j.1151-2916.1993.tb03799.x.

[17] M.A. Chavda, S.A. Bernal, D.C. Apperley, H. Kinoshita, J.L. Provis, Identification of the hydrate gel phases present in phosphate-modified calcium aluminate binders, Cem. Concr. Res. 70 (2015) 21-28. doi:10.1016/j.cemconres.2015.01.007.

[18] N. Ukrainczyk, T. Matusinovic, S. Kurajica, B. Zimmermann, J. Sipusic, Dehydration of a layered double hydroxide-C2AH8, Thermochim. Acta. 464 (2007) 7-15. doi:10.1016/j.tca.2007.07.022.

[19] N.C. Collier, Transition and decomposition temperatures of cement phases - A collection of thermal analysis data, Ceram. - Silik. (2016) 1-10. doi:10.13168/cs.2016.0050.

[20] V.S. Ramachandran, R.M. Paroli, J.J. Beaudoin, A.H. Delgado, 9 - Introduction to Non-Portland Cement Binders and Concrete, in: V.S. Ramachandran, R.M. Paroli, J.J. Beaudoin, A.H. Delgado (Eds.), Handb. Therm. Anal. Constr. Mater., William Andrew Publishing, Norwich, NY, 2002: pp. 355-402. http://www.sciencedirect.com/science/article/pii/B9780815514879500116.

[21] B. Pacewska, M. Nowacka, Studies of conversion progress of calcium aluminate cement hydrates by thermal analysis method, J. Therm. Anal. Calorim. 117 (2014) 653-660. doi:10.1007/s10973-0143804-5.

[22] J. Skibsted, E. Henderson, H.J. Jakobsen, Characterization of calcium aluminate phases in cements by aluminum-27 MAS NMR spectroscopy, Inorg. Chem. 32 (1993) 1013-1027. doi:10.1021/ic00058a043.

[23] I.V. Yakovlev, A.M. Volodin, E.S. Papulovskiy, A.S. Andreev, O.B. Lapina, Structure of CarbonCoated C12A7 Electride via Solid-State NMR and DFT Calculations, J. Phys. Chem. C. 121 (2017) 22268-22273. doi:10.1021/acs.jpcc.7b08132.

[24] D. Müller, A. Rettel, W. Gessner, G. Scheler, An application of solid-state magic-angle spinning 27Al NMR to the study of cement hydration, J. Magn. Reson. 1969. 57 (1984) 152-156. doi:10.1016/00222364(84)90248-8. 